\title{
Trapping of Massive Thrombus in an Inferior Vena Cava Filter: Treatment with Additional Filter Placement and Aspiration Thrombectomy ${ }^{1}$
}

\author{
Jin Soo Choi, M.D., Young Whan Kim, M.D., Won Hyun Cho, M.D. ${ }^{2}$, \\ Hyong Tae Kim, M.D. ${ }^{2}$, Ja Hyun Koo, M.D. ${ }^{2}$, Seong Ku Woo, M.D.
}

\begin{abstract}
For the patients suffering from extensive deep vein thrombosis (DVT), the placement of an inferior vena cava (IVC) filter in conjunction with anticoagulant therapy has been used to prevent pulmonary embolisms. However, for the patients who anticoagulant is contraindicated or if this is complicated, the use of an IVC filter without concurrent anticoagulation may become the sole treatment for pulmonary embolisms. In this situation, the thrombi trapped in the IVC filter may cause significant clinical problems. We report here on a case of IVC filter thrombosis that was successfully treated by aspiration thrombectomy after placing another filter proximal to the previous filter.
\end{abstract}

Index words : Venae cavae, filters

Veins, thrombosis

Interventional procedures

Thrombectomy

The IVC filter offers a safe and effective means for preventing pulmonary emboli and it further reduces the complications of DVT comparing with the classic technique such as caval interruption (1). Even with the goal of preventing thrombus propagation, the thrombosis of the filter insertion site, DVT and vena caval occlusion have been the potential complications of the filters (1). All the currently available filters have been considered to have similar caval thrombosis rates, but they have shown a wide range, from $1 \%-24 \%$, in the reported literature $(2,3)$. Treatments for caval thrombosis include early infusion of local thrombolytic agent, early thrombectomy and long-term anticoagulation, but if the

${ }^{1}$ Department of Diagnostic Radiology, Keimyung University School of Medicine

${ }^{2}$ Department of Surgery, Keimyung University School of Medicine

Received September 24, 2005 ; Accepted January 6, 2006

Address reprint requests to : Jin Soo Choi, M.D., Department of

Diagnostic Radiology, Dongsan Medical Center, Keimyung University

College of Medicine, 194, Dongsan-dong, Junggu, Daegu 700-712, Korea

Tel. 82-53-250-7767 Fax. 82-53-250-7766 E-mail: jschoi@dsmc.or.kr patients have no clinical symptoms or persisting contraindication to anticoagulation, they can be followed up without any specific treatment. The recent advances in interventional radiology have given us another solution, i.e., aspiration thrombectomy with protection from propagation of thrombus via the insertion of another temporal filter. We report here on a case of a massively thrombosed filter-bearing IVC with pulmonary embolism, and this was successfully treated with another filter placement and aspiration thrombectomy.

\section{Case Report}

A 77-year-old man came to our hospital and presented with dyspnea. His medical history included cerebral infarction, congestive heart failure and atrial fibrillation. Three years prior to admission, he developed a swelling of the lower extremity. Doppler sonography and computed tomography (CT) confirmed the presence of DVT in the lower extremity (Fig. 1A, B). 

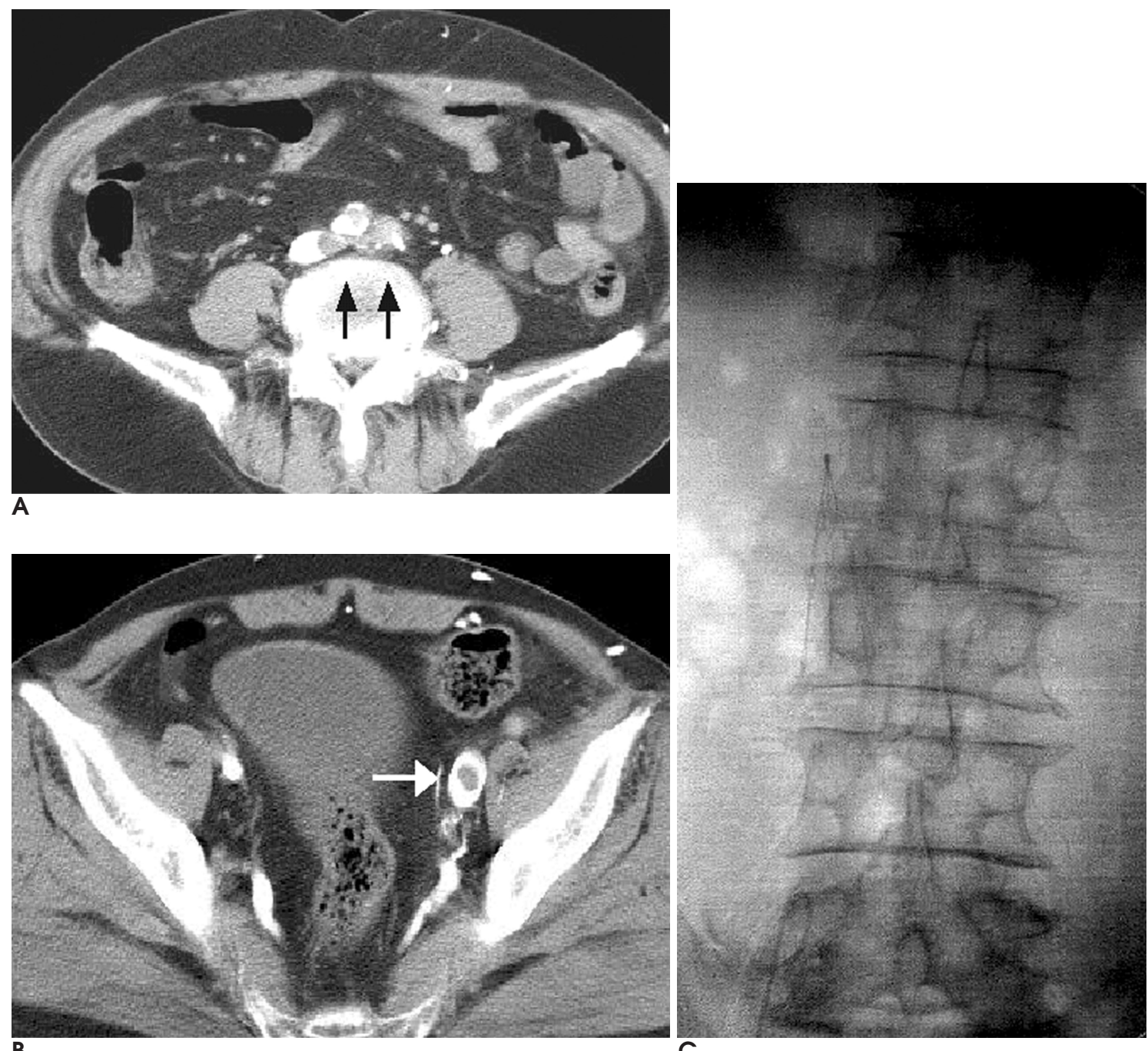

Fig. 1. The contrast-enhanced CT scans in the lower abdomen show thrombotic filling defects (arrows) in the iliofemoral vein (A, B). A Greenfield IVC filter was deployed at the infrarenal level via a right internal jugular approach (C).
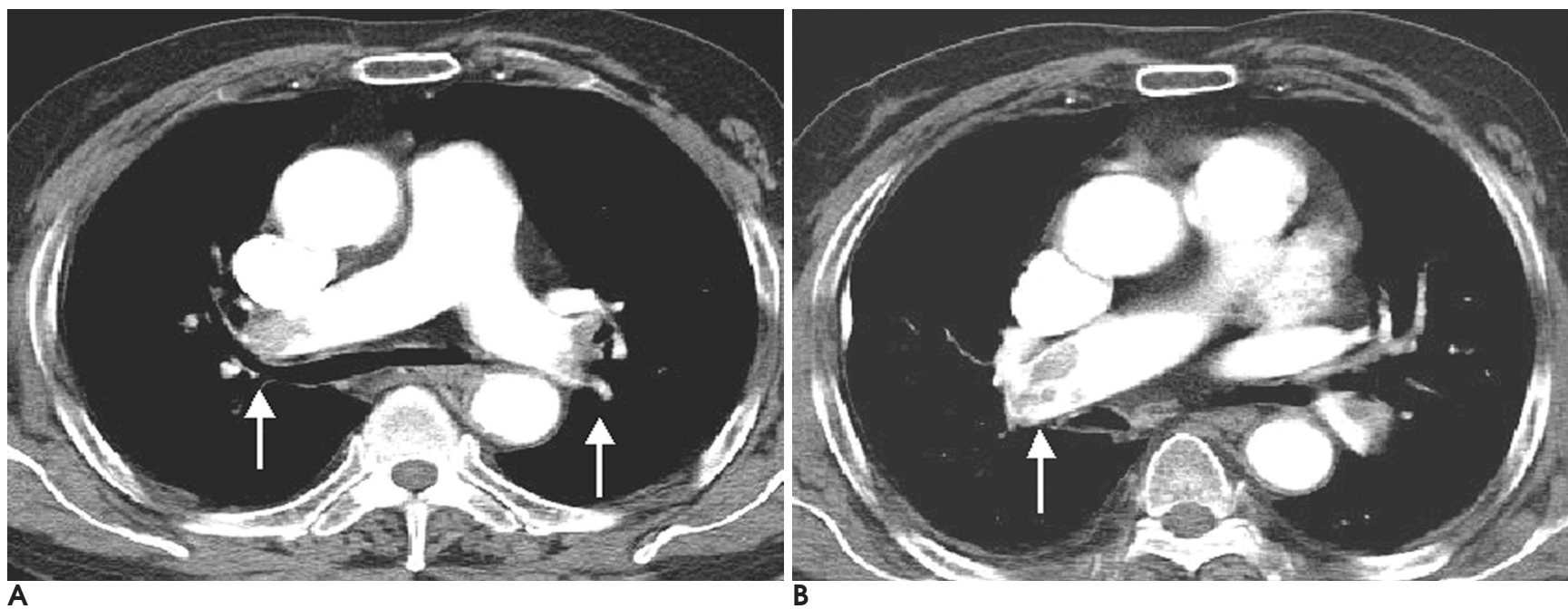

Fig. 2. The contrast-enhanced CT scans show thrombi in the main pulmonary artery and the interlobar artery (arrows). 
Because he suffered with gastric ulcer, catheter-directed thrombolysis was not performed due to concerns about gastrointestinal bleeding, and he was scheduled to undergo IVC filter placement and anticoagulation therapy. Using a standard percutaneous procedure though the right common femoral vein under fluoroscopic guidance, vena cavography was performed using a $5 \mathrm{Fr}$ catheter prior to deployment of a filter to evaluate the caval size and the presence of congenital anormalies and caval thrombus, and also to locate the renal vein. After a vena cavogram was obtained, the catheter was removed over a 0.035-inch Amplatz Superstiff guide wire (Meditech, Watertown, MA, U.S.A.) and a 3- $4 \mathrm{~mm}$ skin incision is made along the guide wire. The long $12 \mathrm{Fr}$ sheath was introduced under fluoroscopic guidance over a standard 0.035-inch guide wire to the intended implantation site in the IVC. After removing the guide wire, the filter was introduced into the sheath and next advanced to the tip of the sheath by means of the pusher. Once it was determined that the filter was in the correct position in the IVC, the sheath was then retracted. By this means, a Greenfield filter (Medi-Tech, Watertown, MA, U.S.A.) was deployed immediately below the infrarenal IVC at the level of L2/3, about $2 \mathrm{~cm}$ inferior to the renal orifice. Caval perforation, leg asymmetry and tilting of the filter were evaluated via a post placement cavogram that was performed immediately after placement. Anteroposterior and lateral projection plain radiography was obtained to determine the final position of the filter in the IVC (Fig. 1C). He was maintained on anticoagulation following filter placement. The dose of anticoagulant (Warfarin sodium, Daewha, Seoul) was $3.75 \mathrm{mg} /$ day for 6 months.

After three months of anticoagulation therapy, he de-

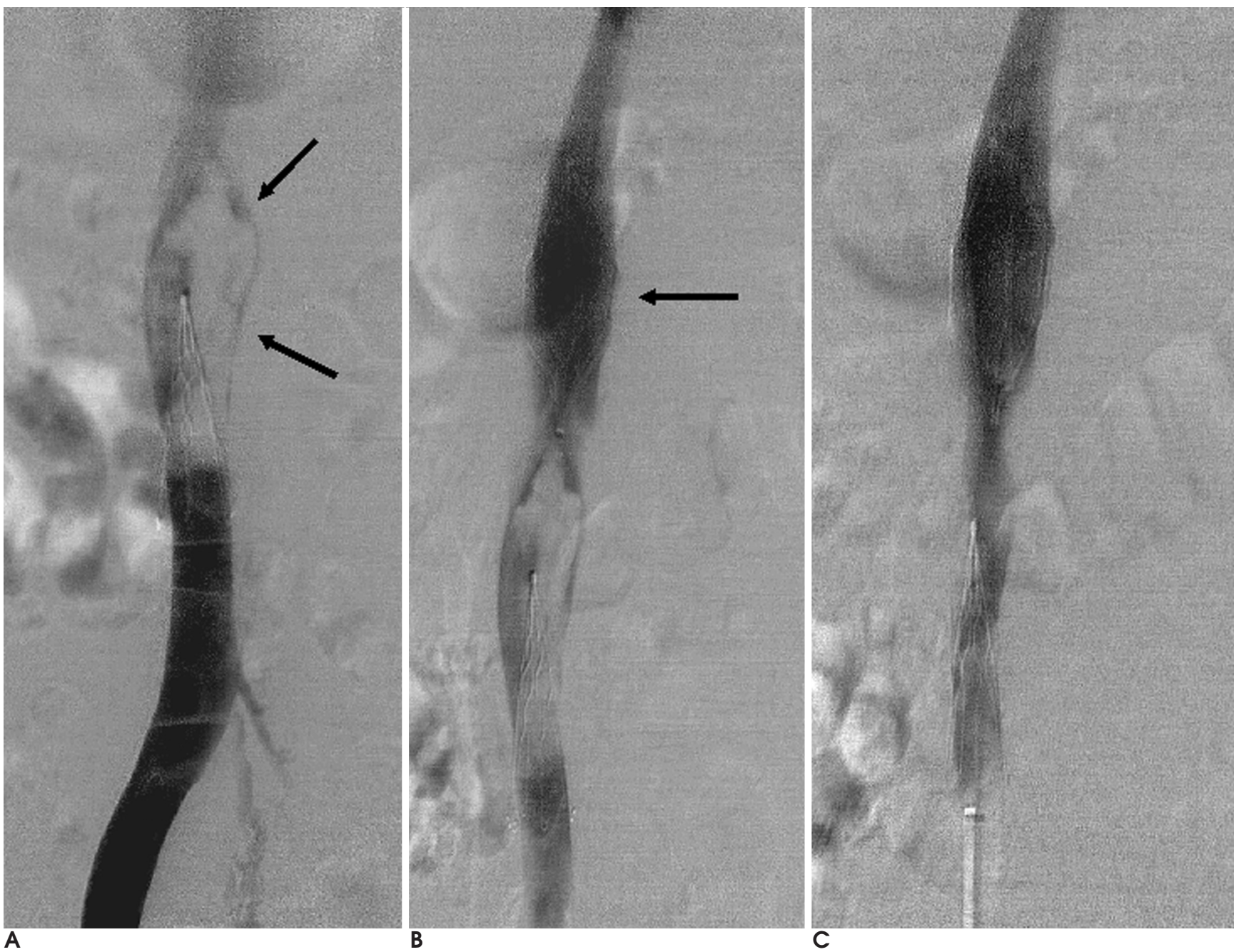

Fig. 3. The findings of digital subtraction venography. It demonstrated an extensive thrombosis of the Greenfield filter-bearing IVC (arrows) with a cephalic extension to the level of the renal vein orifice (A). Before aspiration thrombectomy, another IVC filter (arrow) was inserted at a suprarenal position via a right jugular approach to prevent pulmonary embolism (B). The thrombus was cleared after aspiration thrombectomy with using an 8 Fr Desilet-Hoffman sheath (C). 

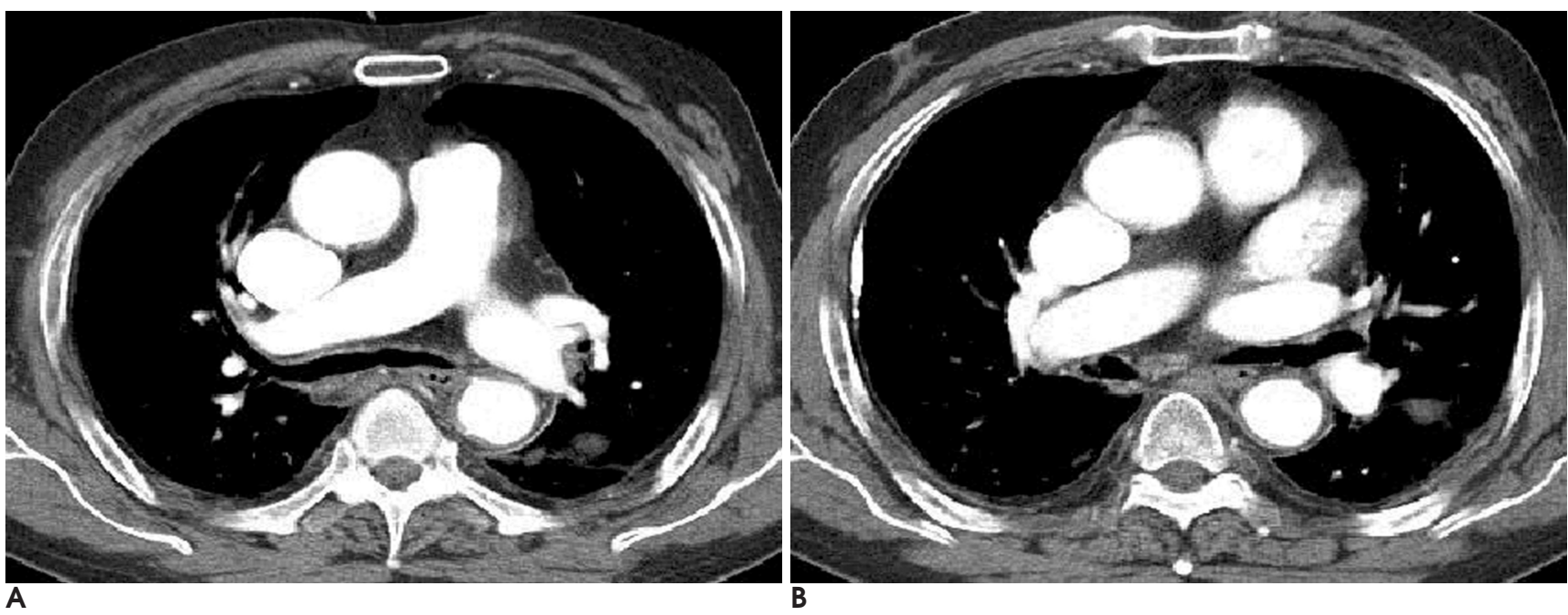

Fig. 4. The CT scans of the chest show the complete resolution of thrombus in the pulmonary artery.

veloped nausea; we stopped the medication and the symptoms disappeared. However, he presented with dyspnea two months before the next scheduled visit to the hospital. Multiple thrombi were demonstrated in the main pulmonary artery and in both interlobar arteries on the contrast enhanced CT scan of the chest (Fig. 2A, B).

A venacavogram performed though the right femoral vein with a $5 \mathrm{Fr}$ pigtail catheter placed below the filter revealed that a massive thrombus was captured in the filter with the cranial extension of the thrombus beyond the level of the filter (Fig. 3A). We planned an aspiration thrombectomy procedure with a Desilet-Hoffman sheath. However, the possibility of distal embolization during aspiration thrombectomy was one of our major concerns, as the shower of emboli might cause a fatal pulmonary embolus during the procedure. A temporary IVC filter was planed to prevent a thrombectomy-related pulmonary embolism, but the device was not available and so we deployed an additional permanent IVC filter. By using a standard percutaneous procedure, the 6 Fr sheath was introduced under fluoroscopy though the right jugular vein over a standard 0.035-inch guide wire to the intended implantation site in the IVC. After removing the guide wire, the filter was introduced into the sheath and then advanced to the tip of the sheath by means of the pusher. A Trap Ease filter (Cordis, Miami, FL, U.S.A.) was successfully deployed at the suprarenal IVC (Fig. 3B). Aspiration thrombectomy was performed with an 8 Fr Desilet-Hoffman sheath /COOK, Bloomington, IN, U.S.A.) via the right common femoral vein. Successful removal of the thrombus in the original IVC filter was achieved along with the cranial extension of the thrombus beyond the level of the filter. The extracted specimen showed a red thrombus and the amount of thrombus was $10 \mathrm{gm}$. A venacavogram performed after the procedure showed restoration of IVC flow without residual thrombus (Fig. 3C).

A CT scan obtained 6 months after anticoagulation therapy revealed the complete resolution of thrombus in the pulmonary artery (Fig. 4A, B).

\section{Discussion}

Since the late 1960s, IVC filters have been available for the prevention of pulmonary embolism in patients with DVT (4). A recent clinical trial has documented the effectiveness of IVC filters for reducing the initial symptomatic or asymptomatic pulmonary embolisms that are without major complications (5). However, repeated trapping of emboli by the IVC filter might cause thrombosis around the filter and the IVC in about $5 \%$ of the patients with implanted Greenfield filters $(5,6)$. The incidence of IVC thrombosis, though it is uncommon after IVC filter insertion, will increase up to $15.3 \%$ if concurrent anticoagulation is not administered (6). The development of IVC filter thrombosis can markedly increase the incidence of pulmonary embolism to as high as $33 \%$ (7).

There are many treatment options available for IVC and IVC filter thrombosis, including systemic anticoagulation, systemic thrombolytic therapy, surgical thrombectomy, catheter directed thrombolysis and endovascular mechanical thrombectomy (8). Systemic anticoagulation and thrombolysis are contraindicated for the patients with recent intracranial hemorrhage or gastrointestinal bleeding. Moreover, it is found that an ilio- 
caval thrombosis will extend centrally in approximately 28- $38 \%$ of anticoagulated patients despite adequate therapy (8). The use of a systemic thrombolytic agent is also only minimally effective in lysing a thrombus in the iliac veins or IVC. Surgical thrombectomy is highly invasive and this is not widely performed. The patients in the recent reports, although their numbers were small, were initially treated with catheter directed thrombolysis to treat IVC thrombosis in the filter-bearing cavae $(8$, 9). If residual thrombus was present, balloon maceration was performed to encourage greater thrombolytic efficiency, and then mechanical thrombectomy (MT) was performed. In case of contraindications to thrombolytic therapy, MT was performed without any accompanying pharmacologic thrombolysis for the primary treatment of an acutely thrombosed IVC. There is a potential risk that the MT device may catch on to one of the struts of the IVC filter during catheter manipulation. This could create difficulties in withdrawing the devices or it could result in filter migration. There is a case report on the entanglement of the steel injection channel of a Hydrolyser catheter on a strut of a Gianturco Z-stent that was placed in the SVC, which could only be dissociated with great technical difficulty (8).

Catheter-directed thrombolysis has been shown to be effective and safe for the management of IVC thrombosis (10). However, we are still concerned about the potential systemic effect of a regionally infused thrombolytic agent, which may induce catastrophic intracranial hemorrhage or gastrointestinal bleeding. Mechanical thrombectomy devices weren' $t$ available in our country at that time and they are also very expensive, and for these reason our first line of treatment is generally aspiration thrombectomy. We didn't use a thrombolytic agent.

In this case, we performed aspiration thrombectomy with a Desilet-Hoffman sheath. However, the possibility of distal embolization during aspiration thrombectomy was one of our major concerns, as the shower of emboli might cause a fatal pulmonary embolus during the procedure. We wanted to deploy another IVC filter to prevent any thrombectomy related pulmonary embolism, but it was not available and so we deployed an additional permanent IVC filter based on the symptomatic pulmonary embolism, the aspiration thrombectomy and the patient's older age. During two years follow up, there is no specific problem with the IVC filter.

In conclusion, we were able to achieve technical success for recanalization of the thrombosed IVC filter and we demonstrated clinical improvement of the symptoms.

\section{References}

1. Joels CS, Sing RF, Heniford BT. Complications of inferior vena cava filters. Am J Surg 2003;69:654-659

2. Millward SF, Peterson RA, Moher D, Lewandowski BJ, Burbridge BE, Aquino J, et al. LGM (Vena Tech) vena caval filter: experience at a single institution. J Vasc Interv Radiol 1994;5:351-356

3. Greenfield LJ, Proctor MC. Cho KJ, Cutler BS, Ferris EJ, McFarland D, et al. Extended evaluation of the titanium Greenfield vena cava filter. J Vasc Surg 1994;20:458-464

4. Greenfield LJ, Michna BA. Twelve-year clinical experience with the Greenfield vena cava filter. Surgery 1988;104:706-712

5. Decousus H, Leizorovicz A, Parent F, Page Y, Tardy B, Girard P, et al. A clinical trial of vena caval filters in the prevention of pulmonary embolism in patients with proximal deep-vein thrombosis. N Engl J Med 1998;338:409-415

6. Becker DM, Philbrick JT, Selby JB. Inferior vena cava filters: indications, safety, and effectiveness. Arch Intern Med 1992;152:19851994

7. Tardy B, Mismetti P, Page Y, Decousus H, Da Casta A, Zeni F, et al. Symptomatic inferior vena cava filter thrombosis: clinical study of 30 consecutive cases. Eur Respir J 1996;9:2012-2016

8. Poon WL, Luk SH, Yam KY, Lee AC. Mechanical thrombectomy in inferior vena cava thrombosis after caval filter placement: a report of three cases. Cardiovasc Intervent Radiol 2002;25:440-443

9. Vedantham S, Vesely TM, Parti N, Darcy MD, Pilgram TK, Sicard GA, et al. Endovascular recanalization of the thrombosed filterbearing inferior vena cava. J Vasc Interv Radiol 2003;14:893-903

10. Angle JF, Matsumoto $\mathrm{AH}$, AI Shammari MA, Hagspiel KD, Spinosa DJ, Humphries JE. Transcatheter regional urokinase therapy in the management of inferior vena cava thrombosis. $J$ Vasc Interv Radiol 1998;9:917-925 


\title{
다량의 혈전을 형성한 아래대정맥필터: 아래대정맥필터 추가 삽입과 흡인 혈전제거술을 이용한 치료 ${ }^{1}$
}

\author{
${ }^{1}$ 계명대학교 의과대학 진단방사선과학교실 \\ ${ }^{2}$ 계명대학교 의과대학 외과학교실
}

\section{최진수. 김영환. 조원현 ${ }^{2}$ 김형태 ${ }^{2}$. 구자현? ${ }^{2}$ 우성구}

다량의 깊은 정맥혈전증(DVT) 과 동반된 폐색전증의 치료에 아래대정맥필터 삽입과 항응고제를 사용해왔다. 그 러나 아래대정맥필터를 삽입한 환자에서 항응고제의 사용이 금기가 되거나 합병증이 발생하였으면, 아래대정맥필 터만으로 폐색전증의 치료가 이루어지며 이러한 경우 아래대정맥필터에 포획된 혈전이 심각한 임상적 문제를 야기 할 수 있다. 저자들은 아래대정맥필터 삽입 후 자발적으로 항응고제를 투여하지 않은 환자에서 아래대정맥필터에 다량의 혈전과 폐색전증이 발생하였고 아래대정맥필터 추가 삽입과 흡인 혈전제거술을 시행하여 성공적으로 혈전 제거를 하였기에 이를 보고하고자 한다. 